\title{
Use of Quantitative Uncertainty Analysis to Support M\&V Decisions in ESPCs
}

\author{
Paul A. Mathew, Ph.D., Lawrence Berkeley National Laboratory \\ Erick Koehling, P.E., EMP2, Inc. \\ Satish Kumar, Ph.D., Lawrence Berkeley National Laboratory
}

\begin{abstract}
Measurement and Verification (M\&V) is a critical element of an Energy Savings Performance Contract (ESPC) - without M\&V, there is no way to confirm that the projected savings in an ESPC are in fact being realized. For any given energy conservation measure in an ESPC, there are usually several $M \& V$ choices, which will vary in terms of measurement uncertainty, cost, and technical feasibility. Typically, M\&V decisions are made almost solely based on engineering judgment and experience, with little, if any, quantitative uncertainty analysis (QUA).

This paper describes the results of a pilot project initiated by the Department of Energy's Federal Energy Management Program to explore the use of Monte-Carlo simulation to assess savings uncertainty and thereby augment the $M \& V$ decision-making process in ESPCs. The intent was to use QUA selectively in combination with heuristic knowledge, in order to obtain quantitative estimates of the savings uncertainty without the burden of a comprehensive "bottoms-up" QUA.

This approach was used to analyze the savings uncertainty in an ESPC for a large federal agency. The QUA was seamlessly integrated into the ESPC development process and the incremental effort was relatively small with user-friendly tools that are commercially available. As the case study illustrates, in some cases the QUA simply confirms intuitive or qualitative information, while in other cases, it provides insight that suggests revisiting the M\&V plan. The case study also showed that $M \& V$ decisions should be informed by the portfolio risk diversification. By providing quantitative uncertainty information, QUA can effectively augment the M\&V decisionmaking process as well as the overall ESPC financial analysis.
\end{abstract}

\section{Introduction}

Energy Savings Performance Contracts (ESPC) are a flexible and effective tool to finance energy efficiency projects. While they specify general terms and conditions for the contract between the customer and the energy services company (ESCO), the contract leaves broad latitude to customize specifics such as measurement and verification $(\mathrm{M} \& \mathrm{~V})$ requirements.

$\mathrm{M} \& \mathrm{~V}$ is a critical element of an ESPC - without $\mathrm{M} \& \mathrm{~V}$, there is no way to confirm that the projected savings are in fact being realized. Every ESPC under the Federal Energy Management Program (FEMP) is required to have an $\mathrm{M} \& \mathrm{~V}$ plan, which describes how the savings will be verified for each measure, and includes details on the parameters that will be measured, how they will be measured, etc. For any given measure, there are usually several M\&V choices, which will vary in terms of measurement uncertainty, cost, and technical feasibility. At one end of the spectrum, the $M \& V$ plan may simply state that most of the parameters that affect a savings estimate be stipulated for the length of the contract, with as little as only one parameter of the savings estimate being measured. At the other end of the spectrum, $M \& V$ may involve detailed long-term measurements of most parameters. Typically, there is a tradeoff between measurement uncertainty and cost e.g. a savings calculation method that requires spot measurements will typically cost less than one that requires continuous long-term measurements, but will result in greater uncertainty in the expected savings. FEMP has developed several tools to aid the $\mathrm{M} \& \mathrm{~V}$ 
decision-making process for ESPCs [FEMP 2004]. These include the M\&V guidelines, which are based on the International Measurement and Verification Protocol [IPMVP 2001], the Risk/Responsibility Matrix and the M\&V decision support flow chart. These tools mostly provide qualitative guidance, and advocate the use of Quantitative Uncertainty Analysis (QUA) to augment the qualitative guidance. ASHRAE Guideline 14 Annex B [ASHRAE 2002] provides some information and guidance on how to conduct uncertainty analysis for energy savings. As noted in the standard, "[a] proper uncertainty analysis can be very complex and cumbersome especially if the potential user strives to be very meticulous." In practice, QUA is seen as just too complicated and cumbersome, and its use in ESPCs has been minimal. (For some examples on how QUA has been used in ESPCs, see Reddy et al. 1999 and Mathew et al. 2005)

This paper describes a pilot project initiated by FEMP to explore the use of Monte-Carlo simulation to assess savings uncertainty and thereby augment the $M \& V$ decision-making process. Monte-Carlo simulation is a flexible QUA technique that has been widely used for risk analysis in various domains. The intent here is to use QUA selectively in combination with heuristic knowledge, in order to obtain quantitative estimates of the savings uncertainty without the burden of a comprehensive "bottoms-up" QUA.

\subsection{Savings uncertainty vs. M\&V cost tradeoff}

Figure 1 uses a hypothetical example to illustrate how QUA can be used to assess the tradeoff between annual savings uncertainty and annual $M \& V$ cost for alternative $M \& V$ plans for a chiller upgrade project:

- In option $\mathrm{CH}-\mathrm{A}-01$, all parameters are stipulated, resulting in almost no $\mathrm{M} \& \mathrm{~V}$ cost, and an uncertainty of about $\$ 30,000$.

- In option CH-A-02, the uncertainty is just under $\$ 20,000$, for an $M \& V$ cost of $\$ 10,000$.

- In option CH-B-02, the uncertainty is significantly reduced to about $\$ 5000$, for the same $\mathrm{M} \& \mathrm{~V}$ cost.

Note that in all cases, the expected savings is the same. It is the uncertainty that varies. Option $\mathrm{CH}-\mathrm{B}-02$ is superior to option $\mathrm{CH}-\mathrm{A}-02$, because it has lower savings uncertainty for the same $\mathrm{M} \& \mathrm{~V}$ cost. Therefore, the choice is essentially between $\mathrm{CH}-\mathrm{A}-01$ and $\mathrm{CH}-\mathrm{B}-\mathrm{02}$. It is important to note that neither of these two choices is inherently superior to the other. The optimal choice for any given context is a function of risk tolerance i.e. is it worth paying $\$ 10000$ in $M \& V$ costs to reduce the savings uncertainty by $\$ 25,000$ ? To properly answer that question it is helpful to know the probability that uncertainty will be below a risk threshold e.g. what is the probability that the savings shortfall will be more than $\$ 15,000$ ? Or $\$ 20,000$ ? QUA can be used to provide this information. 


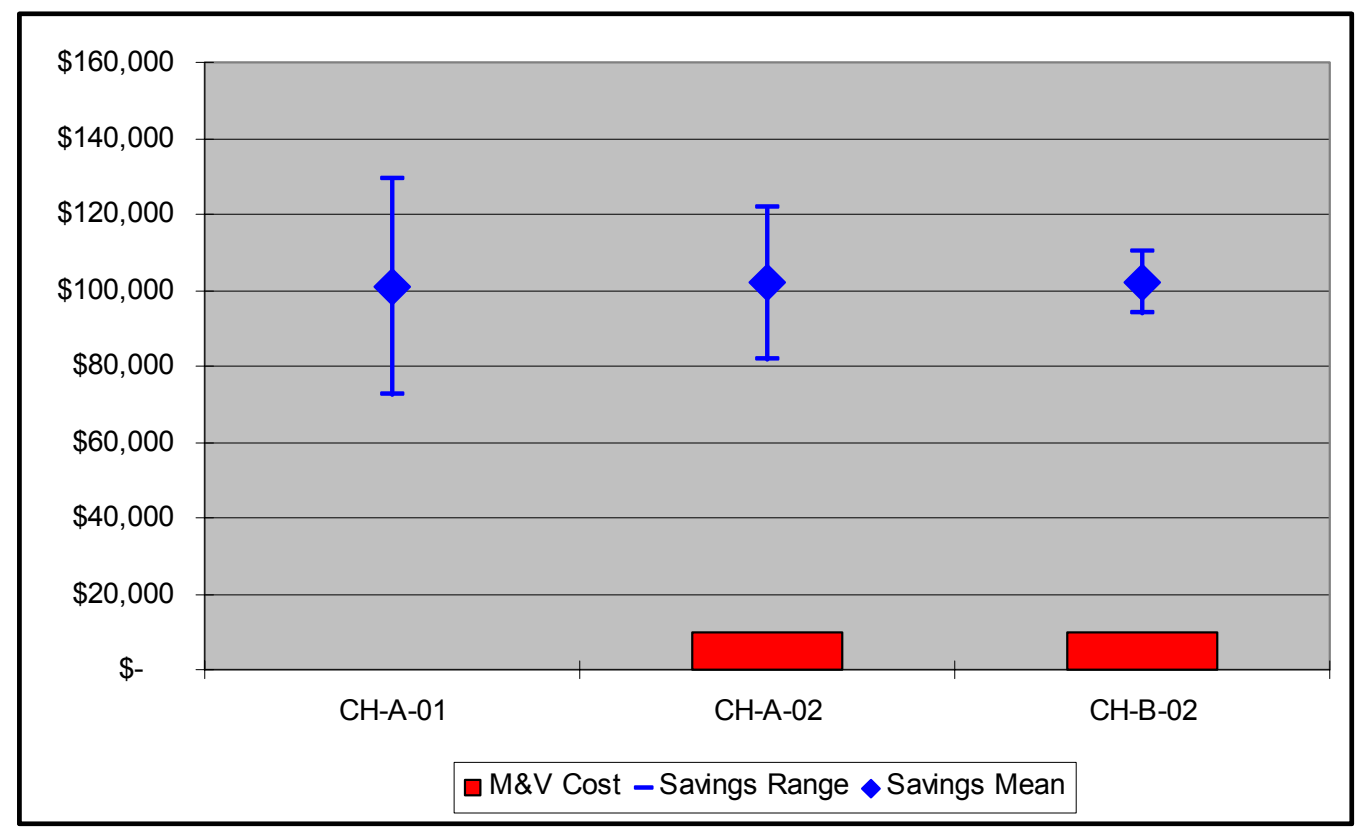

Figure 1. Tradeoff between annual savings uncertainty and annual MEV cost for different $M \mathcal{E} V$ plans for a hypothetical chiller retrofit.

\subsection{Uncertainty analysis using Monte-Carlo Simulation}

Although a fuller description of Monte-Carlo simulation is beyond the scope of this paper, a brief description is provided below.

Consider a lighting retrofit project in which the lighting energy savings is calculated from the following inputs: total wattage before retrofit (kWpre), total wattage after retrofit (kWpost), and operation hours (hrs). Each of these first-order inputs is in turn determined from second-order inputs. For example, total kWpre is determined from the number and wattage of each fixture type. Typically, point estimates of the inputs are used to calculate the savings. In reality, however, there is uncertainty associated with each input.

In Monte-Carlo simulation, the user applies probability distributions to one or more inputs, reflecting the uncertainty of that input (see figure 2). For example, the probability distribution of $\mathrm{kW}$ pre indicates that the estimate of $1800 \mathrm{~kW}$ varies from $1710 \mathrm{~kW}$ to $1890 \mathrm{~kW}$, with a triangular distribution. Probability can similarly be applied to other input parameters. The user then runs the simulation, which yields the probability distribution of energy savings, which in essence describes the savings uncertainty.

QUA with Monte-Carlo simulation can be as simple or complex as the user wants it to be. For example a "bottoms-up" fine-grained approach would involve applying probability distributions to all first and second order inputs in order to capture the full range of the uncertainty (e.g. wattages, fixture counts, operating hours, measurement precision, etc.). At the other end of the spectrum, probability distributions may be applied to just a few first order inputs, in order to capture the uncertainty resulting from those few inputs (e.g. inputs that the ESCO controls and is responsible for). Another aspect is the source of the input probability distributions. These could be derived from empirical data, standard statistical formulae, or may be simply based on engineering expertise. Thus, the analysis is flexible in two ways - with regard to which inputs probability distributions are applied to, and with regard to the source for the probability distributions. 
In this project, the Monte-Carlo analysis was done using CrystalBall ${ }^{\mathrm{TM}}$, which is available as an "add-in" for Excel ${ }^{\mathrm{TM}}$. Since many savings calculations are done in Excel ${ }^{\mathrm{TM}}$, it is relatively easy to do the Monte-Carlo simulation - it essentially involves adding probability distributions to the input cells (e.g. kWpre) and defining the output cell (e.g. \$ savings) for which the uncertainty is information is desired.

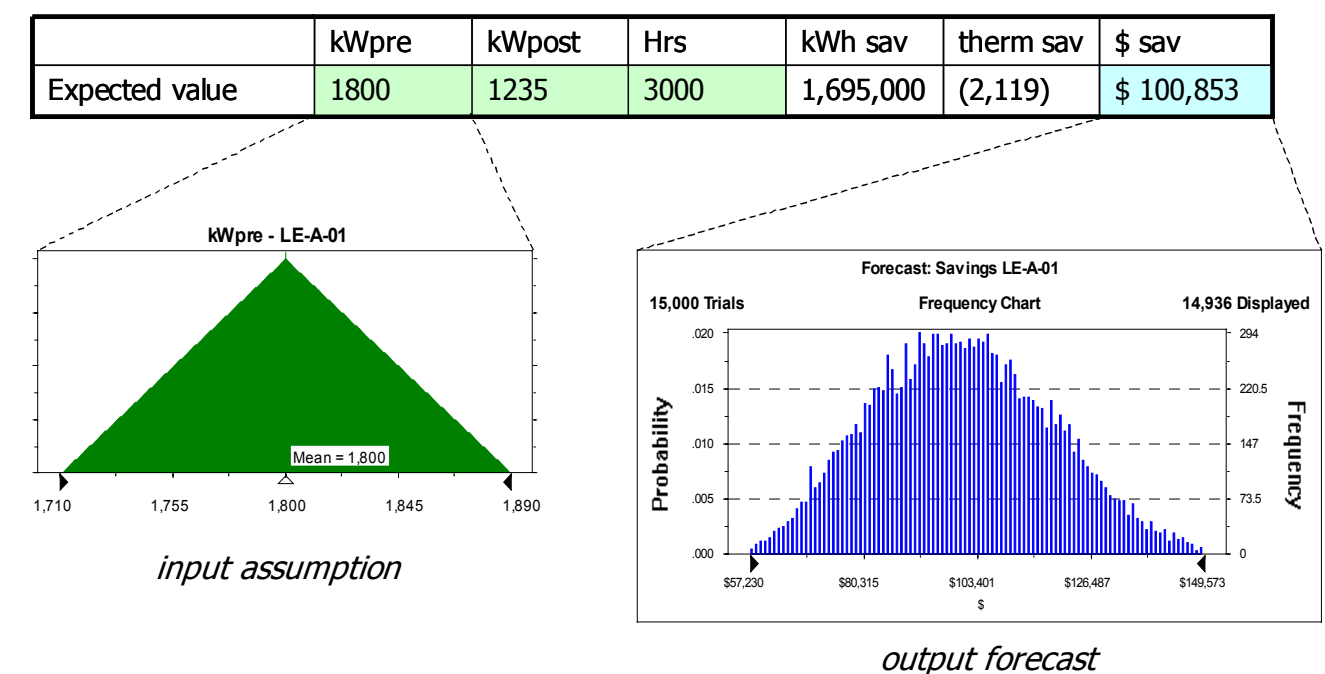

Figure 2. Conceptual illustration of Monte-Carlo simulation for a hypothetical lighting retrofit project, using CrystalBall ${ }^{\mathrm{TM}}$

\section{Case study}

While the theoretical basis for QUA is well established and widely used in other domains [Morgan and Henrion 1990], the primary objective of this pilot project was to assess the practical implications of applying QUA. The QUA project team sought FEMP ESPC projects that: a) were in the initial stages and in which $M \& V$ decisions were not yet made; b) had multiple energysavings measures involving several $\mathrm{M} \& \mathrm{~V}$ choices; and c) had a project facilitator, agency and ESCO that were willing to apply QUA to their ESPC.

The case study described below was for an ESPC at a major federal agency, which included lighting, HVAC, and some cost-avoidance energy conservation measures (ECMs). Table 1 summarizes the ECMs and some basic financial parameters.

Table 1. The ECMs in the case study included a lighting retrofit, several HVAC retrofits, and some costavoidance measures.

\begin{tabular}{|c|c|c|c|c|c|c|c|c|c|c|c|}
\hline $\begin{array}{l}\text { ECM } \\
\text { No. }\end{array}$ & Description & & $\begin{array}{l}\text { Year } \\
\& \text { Water } \\
\text { ings }\end{array}$ & & $\begin{array}{l}\text { Year } \\
\text { \&M } \\
\text { vings }\end{array}$ & & $\begin{array}{l}\text { Cost } \\
\text { voidance } \\
\text { Savings }\end{array}$ & & $\begin{array}{l}\text { ormance } \\
\text { Period } \\
\text { penses }\end{array}$ & \begin{tabular}{|c} 
Net \\
First Year \\
Savings
\end{tabular} & $\begin{array}{c}\text { Installed } \\
\text { Cost }\end{array}$ \\
\hline ECM-L1 & Lighting Improvements & $\$$ & 95,785 & $\$$ & 6,012 & $\$$ & & $\$$ & 7,433 & $\$ 94,364$ & $\$ 1,081,932$ \\
\hline ECM-H1 & Steam Trap Replacements & $\$$ & 122,318 & $\$$ & 5,381 & $\$$ & - & $\$$ & 60,705 & $\$ 66,994$ & 849,224 \\
\hline ECM-H2 & Steam \& Condensate Pipe Insulation & $\$$ & 36,057 & $\$$ & - & $\$$ & - & $\$$ & 2,881 & $\$ 33,176$ & 87,552 \\
\hline ECM-H3 & Chiller controls upgrade & $\$$ & 13,777 & $\$$ & - & $\$$ & - & $\$$ & 2,849 & $\$ 10,927$ & 80,675 \\
\hline ECM-H4 & Ventilation controls upgrade & $\$$ & 30,989 & $\$$ & 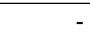 & $\$$ & - & $\$$ & 3,076 & $\$ 27,913$ & 130,281 \\
\hline ECM-H5 & Building HVAC Upgrade & $\$$ & 31,110 & $\$$ & - & $\$$ & - & $\$$ & 5,224 & $\$ 25,886$ & 599,307 \\
\hline ECM-C1 & Water pumping retrofit & $\$$ & 318,209 & $\$$ & $(9,690)$ & $\$$ & & $\$$ & 19,538 & $\$ 288,981$ & $\$ 3,725,698$ \\
\hline ECM-C2 & Process cost-avoidance & $\$$ & $(2,275)$ & $\$$ & $(10,522)$ & & 141,024 & $\$$ & 10,133 & $\$ 118,094$ & $\$ 1,671,570$ \\
\hline ECM-C3 & Sewage project & $\$$ & 173,546 & $\$$ & $(3,300)$ & $\$$ & - & $\$$ & 10,766 & $\$ 159,480$ & $\$ 1,809,721$ \\
\hline & & $\$$ & 819,516 & $\$$ & $(12,119)$ & & 141,024 & $\$$ & 122,605 & $\$ 825,816$ & $\$ 10,035,961$ \\
\hline
\end{tabular}


QUA was done for each of these ECMs, as well as for the project as a whole. For the individual ECMs, the analysis was done at varying levels of granularity, depending on the size of the ECM for larger ECMs, the analysis was more fine grained i.e. probability distributions were applied to more inputs.

The following sections describe the uncertainty analysis for the lighting and steam trap ECMs, as well as the portfolio level uncertainty analysis.

\subsection{Lighting retrofit analysis}

The preliminary lighting $M \& V$ plan called for:

- Measuring the wattage of a sample of the existing lighting fixtures (kWpre). The sampling plan attempted to achieve an overall certainty factor of $80 \%$ with a precision of $20 \%$ i.e. $80 \%$ of the time, the wattage used in the savings calculations will be within $20 \%$ of the measured wattage.

- Measuring the wattage of new fixtures (kWpost), guaranteeing that they will be within 5\% of the wattage used in savings calculations.

- Stipulating the hours of operation (hrs). The analysis assumed an uncertainty of $+/-20 \%$ on operation hours, which is a reasonable estimate based on evidence from similar lighting retrofit projects.

Figure 3 shows the results of a Monte-Carlo simulation on the gross savings (estimated at $\$ 95,785)$, using the above uncertainty data for kWpre, kWpost, and hrs. ${ }^{1}$ The data show that there is a $90 \%$ confidence that the savings will be between $\$ 64,620$ and $\$ 128,964$ i.e. there is a $5 \%$ chance that the savings will be below $\$ 64,620$ and a $5 \%$ chance that it will be above $\$ 128,964$. Given the estimate of $\$ 95,785$, this means that there is a $5 \%$ chance that the savings shortfall could be greater than $\$ 31,165$ (i.e. $\$ 95,785-\$ 64,620$ ). Note that any energy conservation measure will always have some risk of a savings shortfall. QUA essentially helps to better understand the probability of different levels of savings shortfall.

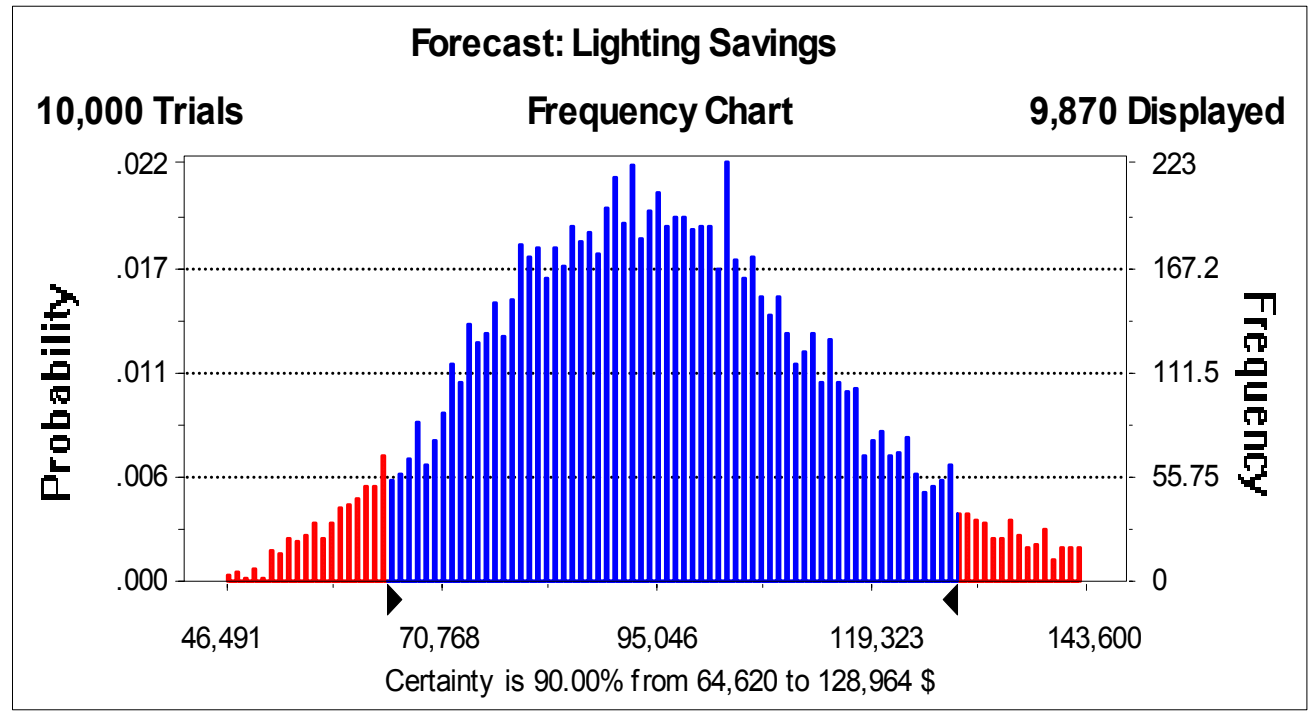

Figure 3 Uncertainty analysis of gross savings for lighting ECM L1, based on proposed MEV plan.

\footnotetext{
${ }^{1}$ The uncertainty in hrs is mostly occupant driven. Additional analysis was done without applying uncertainty to hrs, in order to isolate and analyze the savings uncertainty resulting from equipment wattage alone.
} 
As a test, an alternative scenario was run, in which all pre-installation fixtures were measured, resulting in a $100 \%$ certainty that $\mathrm{kWpre}$ will be within $5 \%$ of the average. The results of this scenario are shown in figure 4 . This shows that the range of uncertainty for the $90 \%$ confidence interval is now $\$ 70,543$ to $\$ 120,627$. Given the estimate of $\$ 95,785$, there is a $5 \%$ chance that the savings shortfall will be greater than $\$ 25,242$. This is about $\$ 6000$ less than the risk with the current $\mathrm{M} \& \mathrm{~V}$ plan. This difference is clearly too small to justify the cost of measuring all preinstallation fixtures, thus validating the current $M \& V$ plan.

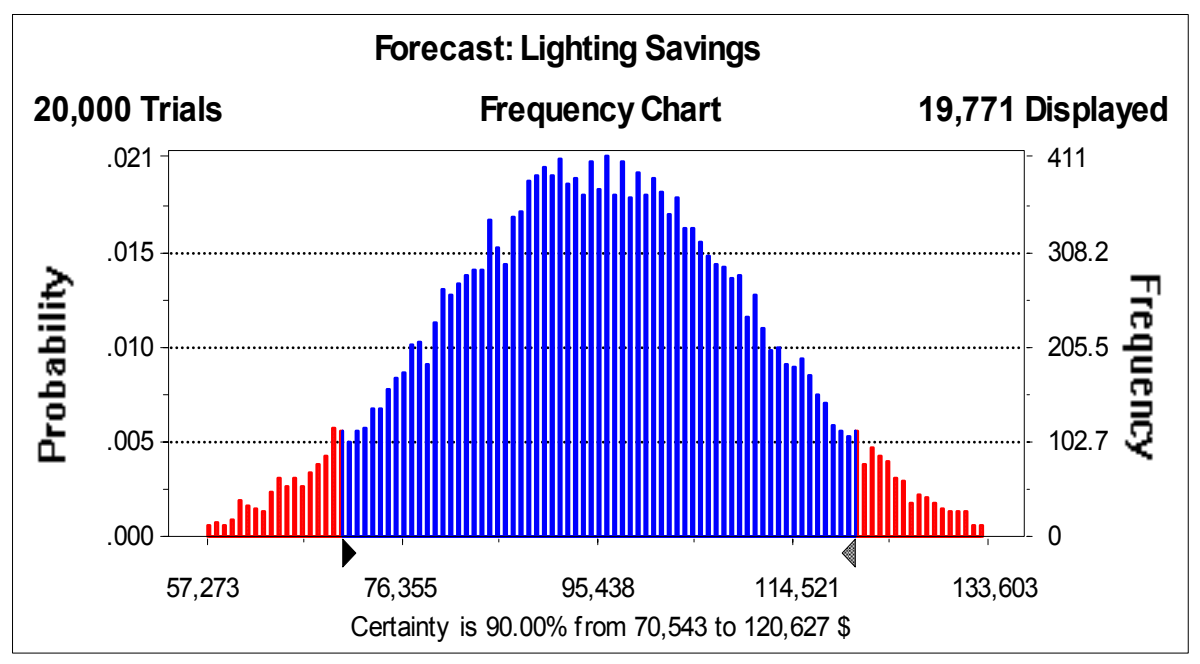

Figure 4. Uncertainty analysis of gross savings for lighting ECM L1, based on alternative MEV plan that measures all pre-installation fixtures.

\subsection{Steam trap replacement}

The key parameters that affect energy savings from steam trap replacements include: number of failed traps, operating hours, steam pressure, and steam flow rate through failed and leaking traps. The uncertainty analysis applied uncertainty distributions to the following parameters:

- Number of failed and leaking traps: the sample size (86 out of 1243 total traps) was used to calculate a population variance, from which a distribution was derived.

- $\quad$ Orifice factor - a variance was applied based on engineering judgment.

There was no uncertainty applied to operation hours, because the steam system operation hours are controlled by the facility (i.e. unlike lighting operating hours, they are not occupant driven).

Figure 4 shows the resulting savings uncertainty distribution. The first point to note is that in this particular case, the estimate $(\$ 122,318)$ is much lower than the average $(\$ 158,000)$. This is because the ESCO used lower (i.e. more conservative) failure and leakage rates than the sample results. The sample indicated $15 \%$ failed traps and $21 \%$ leaking traps. However, the ESCO "discounted" these percentages for the savings and assumed $12.5 \%$ for both failed traps and leaking traps in order to be more conservative. The lower end of the $90 \%$ confidence interval is $\$ 110,187$, which is $\$ 12,131$ below the estimate. 


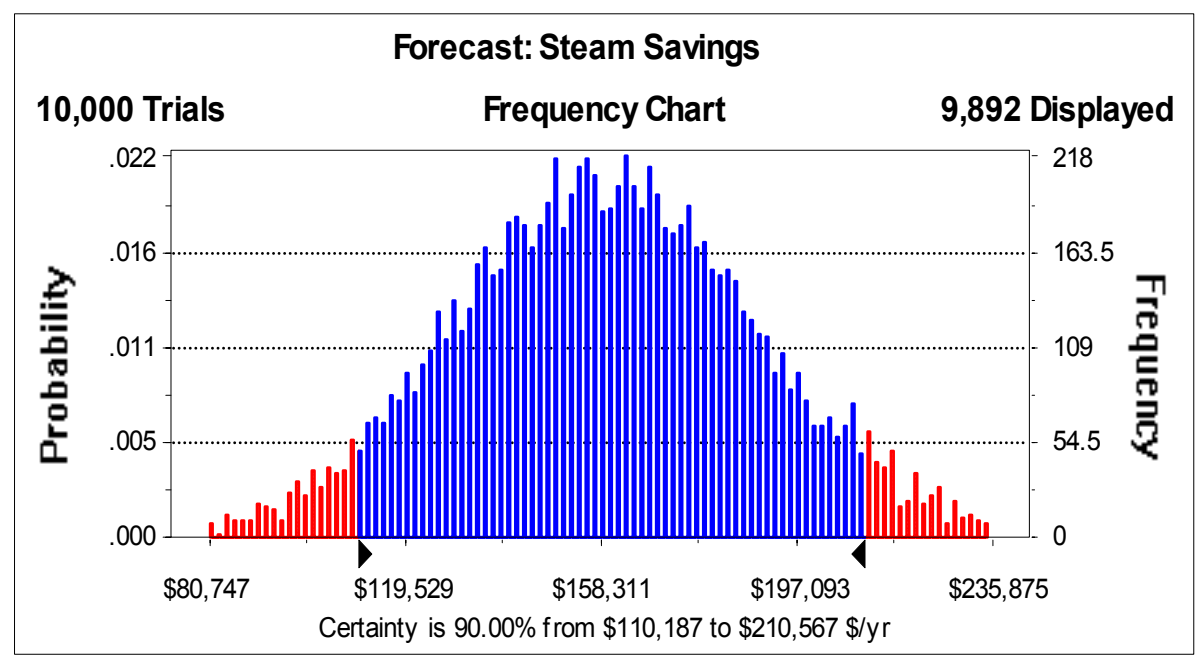

Figure 4 Uncertainty analysis of gross savings for steam ECM-H1, based on a sample of 86 surveyed traps.

Figure 5 shows the uncertainty distribution if the sample size is doubled to 170 traps. In this case, the lower end of the $90 \%$ confidence interval is actually higher than the estimate. This suggests that the ESCO estimate may have been more conservative than necessary in discounting the savings estimate and may be "leaving money on the table". One of the advantages of QUA is that probability distributions can be used to get a better picture of the uncertainty and make a more informed decision about how much to discount savings in such situations.

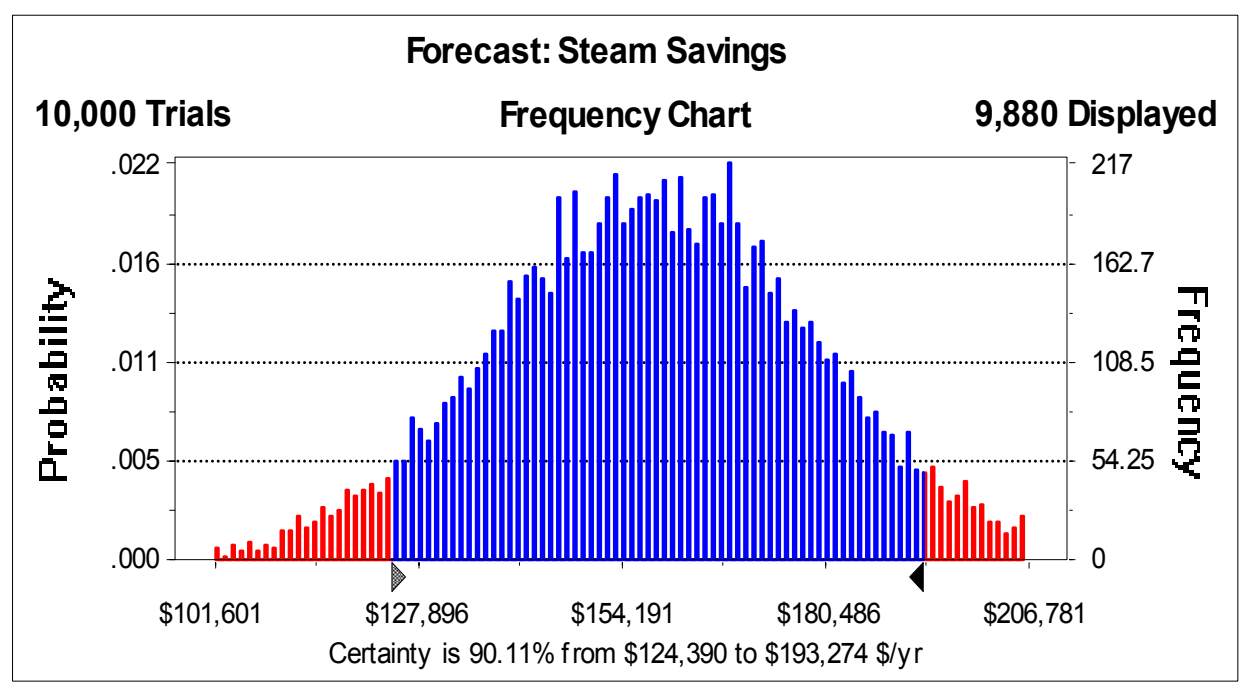

Figure 5 Uncertainty analysis of gross savings for steam ECM-H1, based on a sample of 170 surveyed traps.

\subsection{Impact of portfolio effect in risk diversification}

Besides analysis of the uncertainty for individual measures, QUA is also useful for assessing the impact of the portfolio effect in reducing overall savings uncertainty. Many agencies are primarily interested in the savings uncertainty for the whole portfolio of measures, rather than the individual measures. The simple arithmetic sum of the savings shortfall at the $90 \%$ confidence level for each of the individual measures results in a total of about $\$ 60,000$. However, this is a 
misleading metric, because it does not take into account the risk diversification among measures i.e. a shortfall in one measure may be compensated for by greater than expected savings in another measure (assuming the savings are not correlated). QUA can be used to model the effect of risk diversification. Figure 6 shows the savings uncertainty for the whole portfolio, which indicates that there is a $5 \%$ chance that the portfolio net savings will be less than $\$ 802,528$. Given the portfolio net savings estimate of $\$ 825,816$, this translates into a $5 \%$ chance that the savings shortfall for the portfolio will be greater than $\$ 23,288$ (which is less than half the arithmetic sum of the savings shortfall for the individual measures). This is fairly low relative to the portfolio net savings. However, it should be noted that this analysis assumed no uncertainty (no risk) for the cost-avoidance measures (ECMs C1-3), because budgets for avoided cost are stipulated and funded regardless variation in the avoided cost. In effect, the risk from lighting and HVAC ECMs has been hedged by the lack of risk in the cost-avoidance ECMs. Any change in this assumption would alter the above scenario ${ }^{2}$.

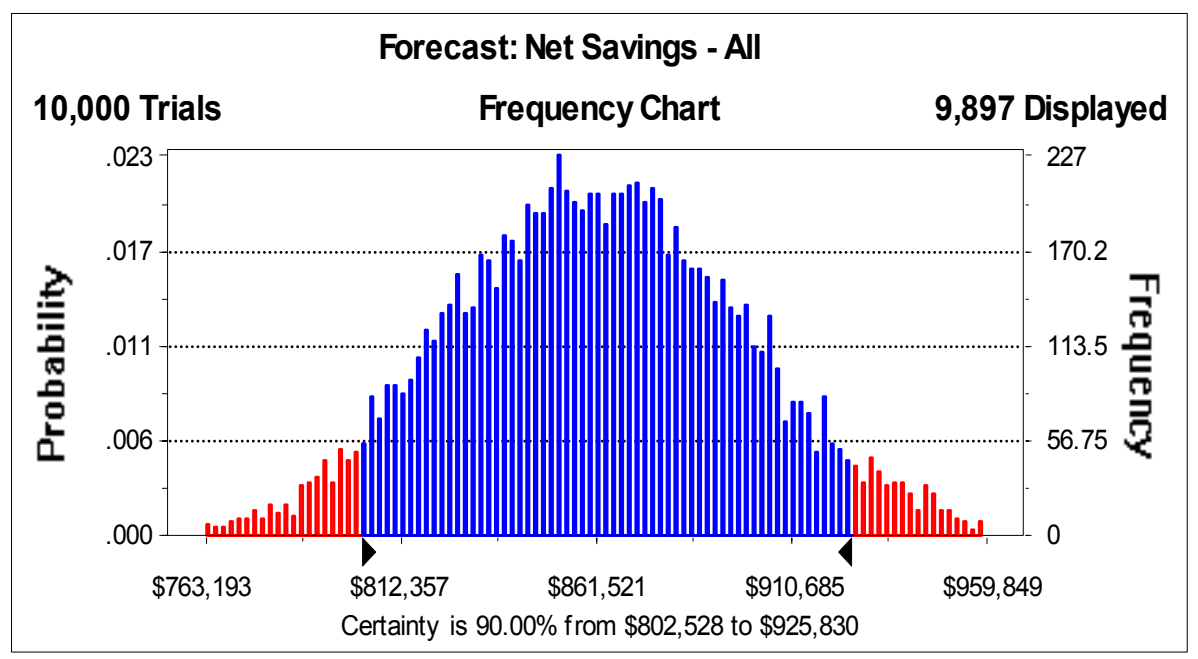

Figure 6 Uncertainty analysis of portfolio net savings, taking into account risk diversification.

\section{Conclusion}

QUA can help the $M \& V$ decision-making process by providing quantitative uncertainty information for individual measures as well as the whole portfolio. QUA can be seamlessly integrated into the ESPC development process and the incremental effort is relatively small with user-friendly tools that are commercially available. The input data requirements for QUA are flexible, and can be based on empirical or theoretical data, as well as engineering judgment. Furthermore, uncertainty information does not have to be applied to all input parameters, which would be a daunting task. Rather, engineering judgment can be used to determine which parameters are most appropriate to apply uncertainty information to, taking into account factors such as relative impact on savings etc.

The application of QUA, like any analysis tool, is both an art and a science. It is therefore important to note that QUA, like any analysis tool, can be misapplied or even abused. While this paper suggests that QUA is valuable for $\mathrm{M} \& \mathrm{~V}$ decision-making, it is not by any means a silver

\footnotetext{
${ }^{2}$ In fact, while conducting the uncertainty analysis for ECM-C9, it was discovered that a contractual anomaly could result in the potential for significantly reduced cost-avoidance savings, and almost double the portfolio savings risk.
} 
bullet that obviates the need for proper contracting and mutual understanding on M\&V issues between the customer and the ESCO.

As the case study illustrated, in some cases the QUA simply confirms intuitive or qualitative information, while in other cases, it provides insight that suggests revisiting the M\&V plan. Furthermore, the case study showed that $M \& V$ requirements should be informed by the portfolio risk diversification.

Additional case studies are required to better understand and document the optimal mix of QUA and heuristic knowledge in ESPC decision-making. The purpose of QUA is not to deterministically derive $\mathrm{M} \& \mathrm{~V}$ requirements. Ultimately, such requirements are a business decision, based on risk analysis and a variety of other factors. QUA simply deepens the information base from which to make those business decisions. The data from QUA can also improve the financial analysis of the ESPC, in that it provides uncertainty data instead of just point estimates. Indeed, uncertainty analysis is critical to bridging the gap between technical and financial analysis in ESPCs [Mills, et al. 2005].

Probabilities direct the conduct of the wise man

- Cicero

\section{Acknowledgements}

This work was supported by the Assistant Secretary for Energy Efficiency and Renewable Energy, Federal Energy Management Program, of the U.S. Department of Energy under Contract No. DE-AC03-76SF00098.

\section{References}

ASHRAE (2002). Guideline 14: Measurement of Energy and Demand Savings. American Society of Heating Refrigeration and Air-conditioning Engineers, Inc., 1791 Tullie Circle, NE, Atlanta, GA 30329-2305.

FEMP (2004). M\&V Guidelines: Measurement and Verification for Federal Energy Management Projects. Available online at http://www.eere.energy.gov/femp/financing/superespcs_measguide.cfm

International Performance Measurement \& Verification Protocol (2001). "Concepts and Options for Determining Energy and Water Savings", US Department of Energy, DOE/GO-1020021554. Available online at www.ipmop.org.

Mathew, P., J.S. Kromer, O. Sezgen, S. Meyers (2005). "Actuarial Pricing of Energy Efficiency Projects: Lessons Foul and Fair," Energy Policy Vol 33/10 pp 1319-1328.

Mills, E., J.S. Kromer, G. Weiss, P. Mathew. (2005) "From volatility to value: analysing and managing financial and performance risk in energy savings projects." Energy Policy, In Press.

Morgan, G., M. Henrion, (1990). Uncertainty. Cambridge University Press.

Reddy, T.A., Haberl, J.S., Elleson, J.S. (1999). "Engineering Uncertainty Analysis in the Evaluation of Energy and Cost Savings of Cooling System Alternatives Based on Field-Monitored Data" ASHRAE Transactions V. 105, pt2. 